\title{
Breaking the waves: a Poisson regression approach to Schumpeterian clustering of basic innovations
}

\author{
Gerald Silverberg and Bart Verspagen *
}

\begin{abstract}
The Schumpeterian theory of long waves has given rise to an intense debate on the existence of clusters of basic innovations. Silverberg and Lehnert have criticised the empirical part of this literature on several methodological accounts. In this paper, we propose the methodology of Poisson regression as a logical way of incorporating this criticism. We construct a new time series for basic innovations (based on previously used time series), and use this to test the hypothesis that basic innovations cluster in time. We define the concept of clustering in various precise ways before undertaking the statistical tests. The evidence we find supports only the 'weakest' of our clustering hypotheses, i.e., that the data display overdispersion. We thus conclude that the authors who have argued that a long wave in economic life is driven by clusters of basic innovations have stretched the statistical evidence too far.
\end{abstract}

Key words: Radical technological change, Long waves, Innovation FEL classifications: $\mathrm{O} 3, \mathrm{O} 4, \mathrm{~N} 10$

\section{Introduction}

Schumpeter was the first economist to place the mechanism of basic innovation at the centre of the discussion about the long-run development pattern of global capitalism. His emphasis on the clustering of basic innovations ${ }^{1}$ is the centrepiece of his theory of long-term economic development expounded at great length in his Business Cycles (Schumpeter, 1939). The introduction of radical innovations triggers a wave of economic activity involving investment-based diffusion driven by temporary monopoly profits and bandwagon-like imitation by other entrepreneurs known as the process of creative destruction. Schumpeter asserted that this process inexorably led to the type of long waves Kondratieff (1926/1935) had claimed to have discovered in the historical data. While his vision was challenged at the time by, for example, Kuznets (1940), Mensch (1975/1979) revived the discussion on

Manuscript received 26 February 2001; final version received 14 December 2001.

Address for correspondence: Bart Verspagen, ECIS-Eindhoven Center for Innovation Studies, PO Box 513, 5600 MB Eindhoven, The Netherlands; email: b.verspagen@tm.tue.nl,www.tm.tue.nl/ecis/bart/

* MERIT, Maastricht University and International Institute of Infonomics (III), and Eindhoven Center for Innovation Studies, respectively. We are indebted to Bart Los and Witold Kwasnicki for helpful discussions, and two anonymous referees for helpful comments. Only the authors are responsible for any controversial opinions or remaining errors, however.

1 '[Innovations] are not evenly distributed in time, but that on the contrary they tend to cluster, to come about in bunches, simply because first some, and then most firms follow in the wake of successful innovation' (Schumpeter, 1939, p. 75). 
clustering of innovations and economic activity using new data and an original hypothesis about causality. This sparked an intensive empirical debate, partly in the pages of this Journal, in the 1980s. Thus the status of the clustering issue has remained a key concept in the debate about long waves and their explication. ${ }^{1}$

The relationship between innovation and long waves is not just a matter of idle historical curiosity. The publicity surrounding the so-called 'new' economy (information and communication technology-ICT, the Internet) as an apparently golden era which seemingly repeals the constraints of the 'old' economy, is a case in point. Does ICT usher in an upswing in economic activity and productivity growth that suspends the orthodox wisdom about the relationship between, for example, employment and inflation, or the fair valuation of equities, or is it only a rerun of previous historical experience with revolutionary and pervasive innovations? Ten Raa and Wolff (2000), for example, find strong productivity effects related to ICT, while Gordon (2000) is much more sceptical after a comparison of the productivity gains of ICT with those of previous technological revolutions.

The perspective of long waves also raises the question as to whether the (supposed) productivity increases related to ICT represent a permanent increment in the long-term rate of technical change, or are simply a passing cyclical phenomenon. The long-wave view would hold that the current period of strong growth is the upswing of the fifth long wave and, hence, that a downswing will inevitably follow it. ${ }^{2}$ The two views are not mutually exclusive. One may imagine the long-run rate of basic innovations as a process with both a positive trend and a cyclical component. In this case, the relevant question becomes whether a model can be formulated that identifies both elements simultaneously.

After a long period of quiescence, a new debate on Schumpeter's hypothesis arose in the 1970 s and 1980s. In this debate, which is summarised in some detail below, much of the empirical argument centred around time series of basic innovations. ${ }^{3}$ These were collected by various authors (who obtained somewhat varying results) on the basis of a historical evaluation of the importance of innovations. The main research question for these authors was whether the number of basic innovations was higher in depression periods than in prosperity periods (a more specific hypothesis than Schumpeter put forward, since he did not relate clustering to specific phases of the economic cycle). The possibility of a (very) long-run trend in the rate of basic innovation did not play any explicit role in this debate.

As early as 1974, Sahal (1974) suggested using a statistical method based on the Poisson and negative binomial distributions to describe time series of incremental innovation. However, this was not taken up in subsequent studies by Kleinknecht (1990) and Solomou (1986), who relied instead on statistical methods based on the normal distribution. Silverberg and Lehnert (1993) highlighted this error and employed more appropriate nonparametric tests based on the Poisson process. In the mean time, Poisson regression has become a standard part of the econometric toolbox (see, e.g., Greene, 1995). Applying this method, the question of whether Schumpeter was right (i.e., basic innovations tend to cluster) can be analysed simultaneously with the question of whether the long-run rate of occurrence of basic innovations is rising. This is what this paper intends to do, working with

\footnotetext{
${ }^{1}$ However, Silverberg and Lehnert (1993), in a formal model, demonstrated that such clustering was not logically necessary to produce long-period quasi-cyclical behaviour of a Schumpeterian economy, even while their empirical analysis did point to non-uniform arrival rates of innovations.

${ }^{2}$ In his historical analysis, Schumpeter observed three long waves since the beginning of modern capitalism. Freeman and Soete (1997), in a similar vein, take note of five long waves, i.e., they argue that two new ones have occurred since the end of Schumpeter's analysis.

${ }^{3}$ Schumpeter distinguished between inventions and innovations, the latter denoting the point in time at which the technology is successfully commercialised.
} 
the same basic innovation databases used by authors such as Kleinknecht and Mensch in the 1970 s and 1980 s.

The rest of this paper is organised as follows. In Section 2, the empirical literature on basic innovation time series and long waves will be briefly reviewed and criticised. On the basis of these results, a number of explicit statistical hypotheses are formulated to capture the ideas that have only been implicit until now in the debate on Schumpeterian basic innovations. Section 3 implements this model in the context of several time series for basic innovations, estimating a model admitting both overdispersion (clustering) and trend components. Section 4 summarises the main findings and draws some conclusions. The two appendices present technical details of the econometric methods and our recompilation of the innovation data.

\section{Innovation time series: review of the literature and shortcomings}

The 1970s and 1980s witnessed a rekindling of the debate on the Schumpeterian hypothesis of clustering of innovations rooted in statistical analysis of real data. The first contribution to this debate was by Mensch (1975/1979), who argued strongly in favour of the Schumpeterian hypothesis that basic innovations tend to be clustered. Moreover, he claimed that this clustering occurs in the depression periods of the long wave. Mensch's theoretical explanation for such clustering was that only in the despair of the depression phase do firms resort to the highly risky strategy of introducing basic innovations (drawing on inventions that may have been made previously). During the upswing and upper turning phase, in contrast, firms focus on squeezing profits out of the dominant technologies, and search activities aimed at basic innovations are at a low level (whether this is perfectly rational or myopic behaviour with respect to the relative costs of the various technological opportunities over the cycle remains open). His approach was to construct a database of basic innovations, and to use a runs test on the resulting time series of the number of innovations occurring each year (using year of innovation rather than year of invention) to test whether the series clustered. A runs test is a test of independence on the assumption of identical distribution, and thus does not control for a trend. On the other hand, it does not require the researcher to impose a periodisation on the data, a defect which, as we shall see, mars the work of later researchers.

While Mensch drew on the work of Jewkes et al. (1958) for his time series, that work was not constructed to be representative, and in particular the datings used and choice of innovations were disputed by Freeman et al. (1982). All such innovation time series, including the ones used below, are naturally subject to limitations. The first limitation concerns the arbitrariness in the selection of innovations and their dates. Second, an end of sample bias may exist, since there is usually insufficient evidence to identify which innovations actually prove to be economically significant in the period close to the researcher's own epoch. Finally, a simple listing of innovations fails to capture their systemic and paradigmatic interrelatedness, the importance of which has been emphasised by Freeman and Perez (1988).

Haustein and Neuwirth (1982) compiled a different time series on basic innovations, and used spectral analysis to test for periodicity in this and other time series related to the long wave. They concluded that there are 'some doubts when looking at the regular patterns of inventions and innovations by Mensch and Marchetti' (p. 67). In other words, their results suggest a less strictly periodic pattern than was suggested by Mensch. 


\section{4}

\section{G. Silverberg and B. Verspagen}

In the mean time, the interpretation of the innovation time series data by Mensch gained support from van Duijn (1983) and Kleinknecht (1981, 1987), who provided more extensive data sets. A further contribution that was critical of the clustering hypothesis was Solomou (1986). He applied a $z$-test to the null hypothesis that the mean number of basic innovations in adjacent periods were drawn from a normal distribution with the same mean, which could not be rejected.

Kleinknecht (1990) responded to this criticism by constructing a new time series of basic innovations that was a compilation of three different time series used earlier (Mensch, Haustein and Neuwirth, van Duijn). He used a similar null-hypothesis to Solomou's, but relied on a $t$-test rather than a $z$-test. His conclusions were strongly in favour of clustering of basic innovations in the depression periods of the long wave. An important element of the differences in the results between Kleinknecht and Solomou lies in the different periodisations they use (as admitted by Kleinknecht, 1990, p. 86). Both Solomou and Kleinknecht use a division of a full cycle into two periods (up and down). Solomou (1986) uses the periodisation proposed by Mensch (1975/1979), while Kleinknecht (1990) relies on two different periodisations (for different lead times of innovation to economic time series), which were both based on his own work (Kleinknecht, 1987).

The methodology of these studies was strongly criticised by Silverberg and Lehnert (1993). They argue that

$z$ and $t$ tests . . are only applicable to a normally distributed random variable. On a priori grounds we have argued that the null hypothesis on innovations must be that they are homogeneous Poisson distributed, however, and a histogram of, for example, the Haustein and Neuwirth data (as well as any of the other series we have examined) confirms that they are anything but normally distributed ... both authors apply their tests to sub samples they claim have been selected on a priori criteria ... In general, the periodisations employed derive from previous authors such as Mensch, whose use of a runs test did not depend on it, or on the examination of growth rates and the addition of a time lag ... growth rates and a moving average of the innovation data may be highly (cross) correlated, so that the selection of a proper lag against variations in the growth rate series may simply be a method to select sub periods of above- and below-average innovation activity even from a completely random series. This fact would further invalidate any means test (even one appropriate to a Poisson process, such as a binomial statistic). (p. 31)

Thus, the statistical methodology used by Solomou and Kleinknecht is flawed, both with regard to the assumed distribution underlying the test statistics, and the particular choice of a periodisation scheme. To overcome these difficulties, Silverberg and Lehnert apply a number of non-parametric tests to the null of a homogeneous Poisson process without imposing a periodisation on the time series. This is convincingly rejected for all series. They then test for the existence of an exponential trend, again using a non-parametric method appropriate for a Poisson process, and show such a trend to be highly significant for all series. The growth rate of the trend is estimated (on the assumption of a non-homogeneous Poisson process with exponentially growing arrival rate) and found to be in the range of $0.5-1 \%$ per annum, depending on the series examined. After eliminating the trend from the data by a process of exponential slowing down of the original time series, the resulting trendless series are still shown to deviate significantly (although less so than non-detrended data) from a time-homogeneous (i.e., non-clustering) Poisson distribution. They concluded that, while to a first approximation these count data appeared to be generated by a Poisson process with an exponentially growing trend, it cannot be determined by these methods whether the statistically significant remaining deviations were indeed periodic or were random clustering resulting from some point process other than Poisson (e.g., negative 
binomial). They suggest further research using a more elaborate modelling strategy based on the Poisson distribution (p. 33) to carry this line of inquiry further.

This advance in the methodological discussion forces us to confront the question of what explicit statistical hypothesis actually corresponds to the Schumpeterian theory of basic innovation, since different variants are conceivable that necessitate different statistical tests. One particularly strong hypothesis, which we shall term the Schumpeter Mark I.0, seems to be implicit in most of the empirical work, although it is not necessarily attributable to Schumpeter himself. This hypothesis might be formulated as follows. Basic innovations are generated by a stochastic process, but one whose arrival rate fluctuates deterministically and strictly periodically with a period of 50-60 years.

A more involved version of this hypothesis, which we shall refer to as Schumpeter Mark I.1, also claims that the arrival rate varies deterministically, but as a function of macroeconomic variables such as the profit rate. The arrival rate will thus have time series properties similar to those of such variables and correlate with them, but not necessarily be strictly periodic. Which way causality runs will be difficult to determine (with Mensch arguing from macroeconomic variables to innovation back to macroeconomic variables, while Schumpeter, as near as we can make out, would only argue from innovation clusters to macroeconomic growth). If the macroeconomy is in fact more or less periodic, then the Schumpeter Mark I.0 and I.1 hypotheses will be almost impossible to distinguish.

Schumpeter (1939) himself appears to argue only that innovations cluster, without any reference to a specific deterministic structure determining when exactly clusters of innovations will occur in time (i.e., in which phase of the economic wave, or even in regularly spaced spells of high and low innovation activity). Such a 'weak' variant of clustering may be consistent with a random clustering pattern, i.e., periods of high and low innovation activity do occur in the data, but there is no regular and predictable mechanism governing their occurrence. We shall classify hypotheses of this kind as Schumpeter Mark II: the stochastic process generating innovations is more complicated than Poisson, and clusters arrive stochastically. ${ }^{1}$ Two variants can be differentiated. Mark II.0 invokes purely random clustering from some additional distribution (such as a negative binomial process where the arrival rate fluctuates according to a Gamma distribution; see Appendix 1 and below). Mark II. 1 calls for the clustering to be initiated by random events, but then obey some sort of causal mechanism that makes this random event 'persist' for some time. An example of such a process would be an autoregressive process, in which (with positive autocorrelation) a single random event tends to be followed by higher activity in the periods immediately following. To see how such a hypothesis might be consistent with at least part of Schumpeter's arguments, recall the quotation from Schumpeter (1939) in fn. 1 on p. 671.

\section{Empirical results}

As we have argued above, innovations are intrinsically count data generated by a point process. Sahal (1974) proposed using the Poisson model to examine the characteristics of various time series of innovations in different industries. His conclusion was that invention is properly characterised as a Poisson random process, but [ . . ] its rate is a function of economic forces' (p. 403). Although Sahal did provide some estimates of parameters related to these economic forces, these were based on ordinary least square methods. However, when the data contain many zero and small integer values, a maximum likelihood

\footnotetext{
${ }^{1}$ In particular: the stochastic process is overdispersed, a term to be explained below.
} 
approach based explicitly on the Poisson distribution is more appropriate. Such a procedure was introduced into the literature on innovation by Hausman et al. (1984). They estimated a model in which the number of patents of a firm is related to the firm's R\&D expenditure. Elaborations on this approach were presented by Crepon and Duguet (1997A, B) and Cincera (1997).

The methods used in this literature, commonly known as 'Poisson regression', are presented in Appendix 1. The Appendix also presents an extension of the methods of Poisson regression to time series analysis, which is of particular importance to the problem at hand. Our aim in this paper will be to apply these statistical tools to the investigation of the hypotheses formulated above.

Like Kleinknecht (1990), we shall use a time series for basic innovations that is created from several other time series introduced by other researchers. This new innovation time series was created by merging the two longest time series available in the literature, i.e., Haustein and Neuwirth's and van Duijn's. Kleinknecht's time series is too short compared to the two other basic innovation time series. Besides the innovations time series, we will also use the time series of important patents as identified by Baker (1976), which was also used by Kleinknecht (1987). The Baker data were not included in the merged innovation time series because they are based on patent data rather than innovation data, and hence are less compatible with the other two time series. Instead, the Baker time series will be treated separately in the statistical analysis.

The construction of our merged innovation time series differs substantially from the Kleinknecht approach. The main difference concerns the overlap, i.e., those innovations which are covered in both sources. Kleinknecht constructs a time series in which the innovations that occur more than once in the three time series he considers are double or triple counted. In other words, he simply adds up the numbers of innovations per year in the three innovation time series. Kleinknecht justifies this procedure by arguing that it provides some implicit weighting scheme, in which the important innovations (i.e., those on which all sources agree) are weighted more heavily.

It is clear that such an implicit weighting procedure introduces an element of extreme arbitrariness. We choose instead to count an innovation only once, even if it is covered by both samples. A complication in this procedure is that, as noted by Kleinknecht, the innovation dates of the same innovation often differ between the two sources. The majority of overlap cases are dated within a range of 10 years, but differences of up to 50 years exist. In all cases, the earliest date was used to assign the innovation to the merged sample. The merged sample contains 88 innovations that occur in both samples, 90 innovations that only occur in the Haustein and Neuwirth sample, and 70 cases that are only listed in the van Duijn sample. The merged series thus has 248 innovations, dating from 1764 to 1976 . The complete listing of all innovations in the merged sample, as well as the original Haustein and Neuwirth and van Duijn sources, together with their assignment to the merged sample, are given in Appendix 2. Following Kleinknecht's terminology, we shall refer to this merged time series as the 'supersample time series'.

Figure 1 shows histograms for the Baker patent time series, the two time series we used to create the 'supersample time series' (Haustein and Neuwirth, and van Duijn), and the 'supersample time series'. The Baker time series runs from 1769 to 1970, and thus comprises 202 years. The Haustein and Neuwirth (1982) data run from 1764 to 1975 (212 years), while van Duijn (1983) covers the period 1811-1971 (161 years).

All three histograms show that the highest frequency is found for zero innovations. Also, 

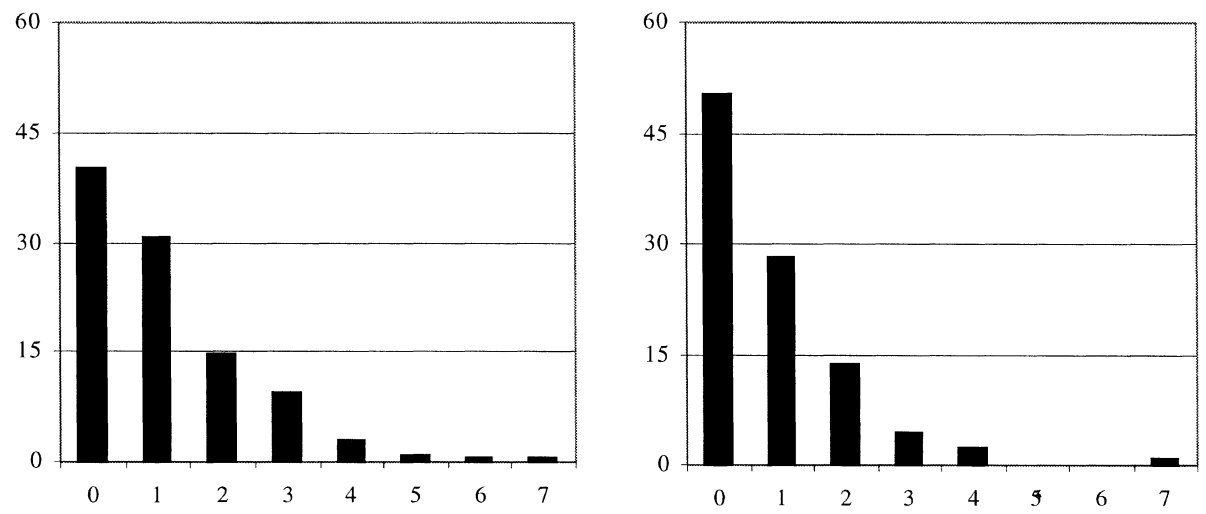

Van Duijn

Super sample


Fig. 1. Histograms of basic innovation time series data, on horizontal axis: number of innovations per year; on vertical axis: percentage share of total sample.

all histograms show mostly declining frequencies for larger numbers of innovations per year. No time series shows more than seven innovations per year (this occurs twice in the Haustein and Neuwirth series). The assumption of normally distributed data clearly must be rejected at face value.

As explained in Appendix 1 in more detail, Poisson regression is a technique aimed at estimating the arrival rate of a certain event. In the present context, the arrival rate can be thought of as the average number of basic innovations per year. It can be modelled either as a constant factor or as dependent on economic variables as well as time. We start by fitting a simple Poisson model with a constant arrival rate (i.e., a time-homogenous process), and then proceed to implement two departures from this simple model. The first generalises the Poisson model to allow the variance of the dependent variable to be larger than the mean (this phenomenon is known as overdispersion, and is discussed in Appendix 1). This is done by fitting a negative binomial model. The second is to estimate the arrival rates (in 


\section{G. Silverberg and B. Verspagen}

both the Poisson and the negative binomial model) as following a time trend. The latter is specified by equating the log of the arrival rate to a polynomial function of time, where we experiment with polynomial degrees up to 3 (a log formulation is used to ensure that the arrival rate is always non-negative). ${ }^{1}$ The results of these estimations are displayed in Table 1.

The hypothesis of a constant arrival rate (time-homogenous Poisson process, or all polynomial terms equal to zero) is obviously rejected. Both for the supersample innovations time series and the Baker patents time series, the exponential quadratic trend emerges as the 'best' model. Entering the third-order term only leaves the linear trend significant, while a second-order polynomial emerges with all coefficients significant. We thus proceed on the assumption that a quadratic trend captures the long-run growth rate of the number of basic innovations in a reasonable way.

Figure 2 displays the raw data and the fitted linear and quadratic exponential trends for the two models (Poisson and negative binomial). The monotonically increasing lines are the fitted linear trends, the lines levelling off towards the end of the period are the estimated quadratic trends. The estimated trends do not differ greatly between the pure Poisson and the negative binomial models. There is, however, a major difference between the linear and quadratic trends. The latter shows a higher level during the period (roughly) 1850 until 1900, and levels off around 1930 (supersample) or 1920 (Baker patents). This would seem to indicate that the rate of basic innovation is slowing down in the 20 th century after a period of relatively rapid increase in the latter part of the 19th century. This phenomenon may, however, be caused by an end of sample bias in the time series caused by the fact that, at the time when the time series were constructed (during the 1970s), it was not yet clear which recent innovations would prove to be basic.

Overdispersion is measured by the significance of the parameter $\alpha$ in the negative binomial model (see Appendix 1 for details). The results differ somewhat between the two time series in this respect. In the case of the supersample of innovations, the negative binomial model is always preferred to the simple Poisson model, as is clear from the fact that the $\alpha$ parameter is always significant (at the $10 \%$ level). In the case of the Baker patent time series, the quadratic and cubic models both yield $\alpha$ s that are significant at a level just above $10 \%$, while the linear exponential trend (10\% level) model and the time-homogenous process ( $1 \%$ level) yield significant $\alpha$ s.

These results have implications for the hypotheses that were introduced above. Specifically, the fact that the negative binomial model is generally preferred over the simple Poisson model points to the fact that the data are in fact overdispersed. In other words, compared with a (time-homogenous) Poisson process, the data display clustering in the sense of random spells of high and low innovation activity. We interpret this as evidence in favour of the Schumpeter Mark II.0 hypothesis.

In order to get a first impression of the deviations from the long-run trend growth rate which bears on the three other hypotheses, an analysis of the autocorrelation of the residuals of the regressions was performed. To this end, the residuals were standardised by dividing them by the estimated standard deviation (square root of the variance). As explained in Appendix 1, in the case of a Poisson process, this implies dividing by the square root of the arrival rate itself (which varies over time when a trend is included). In the case of a negative binomial model, the variance is calculated as $\lambda(1+\alpha \lambda)$, where $\lambda$ is the estimated arrival

\footnotetext{
${ }^{1}$ In the notation of Appendix 1, we thus estimate $\ln \lambda=c+\beta_{1} t+\beta_{2} t^{2}+\beta_{3} t^{3}$ (where $t$ is time, and we set some of the higher-order $\beta$ s to zero in some estimations).
} 


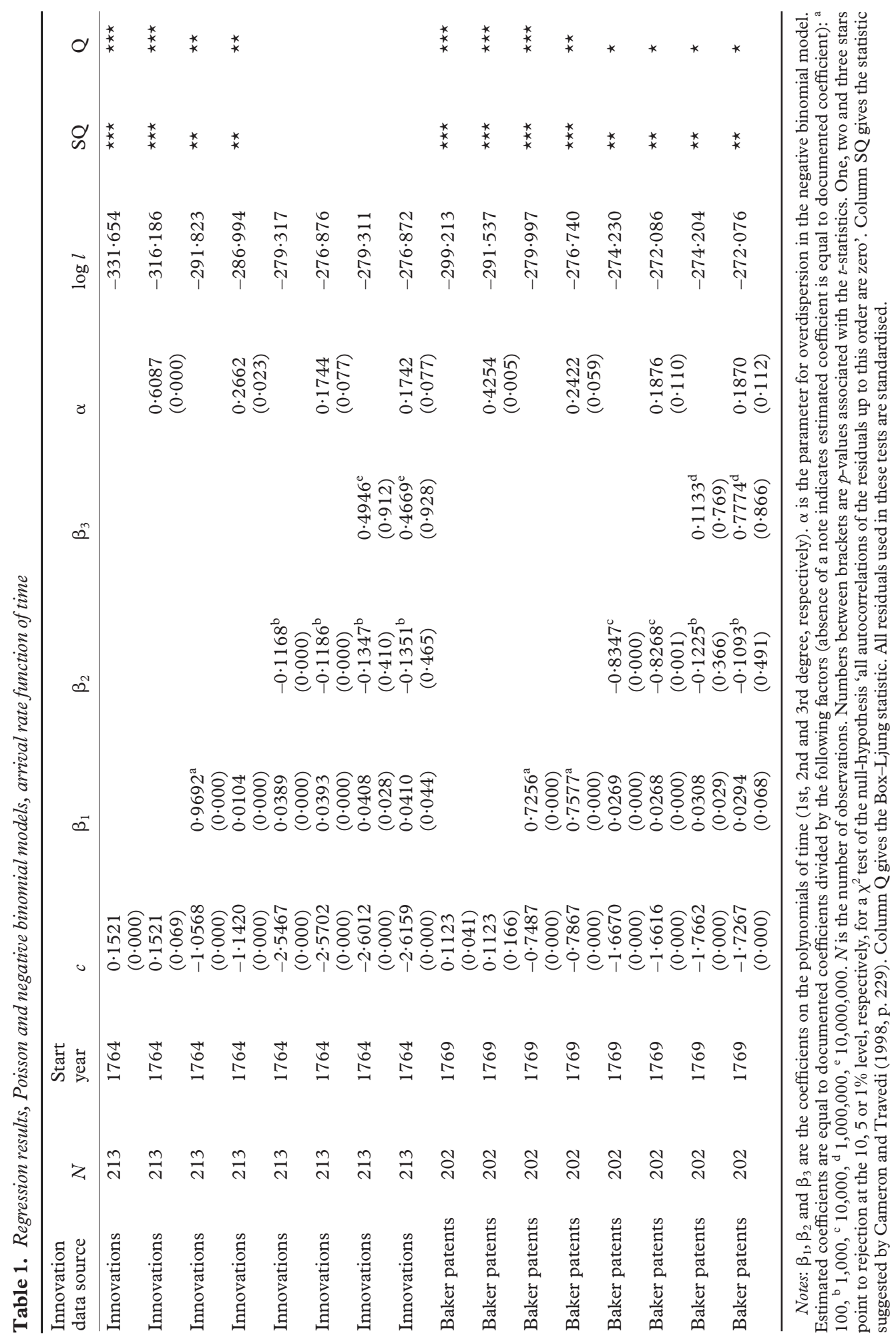


rate, which again varies over time in the event of a time trend. We test for the nullhypothesis that all autocorrelations up to (and including) order $k=(1 \ldots 20)$ are zero using two tests. The first is suggested by Cameron and Trivedi (p. 229), and 'guards against incorrect standardisation' of the residuals. The second is the standard Box-Ljung statistic. Both tests apply a statistic that is $\chi^{2}$ distributed with $k$ degrees of freedom (the maximum order of the autocorrelation process).

The last column in Table 1 gives the significance level at which (if at all) we reject the null-hypothesis of no autocorrelation in the residuals. We used orders up to 20 to test for this. In the case of a time-homogenous process, there is clearly very significant autocorrelation, for both time series (patents and innovations) and both statistical models (Poisson model and negative binomial). When time trends are included, this diminishes, although the extent to which this happens differs greatly between the two time series. With the innovation data, a linear time trend still leaves significant autocorrelation at the $5 \%$ level; for the Baker patent time series at the $1 \%$ level for three of four cases. For higher-order polynomial

(a) Innovation supersample

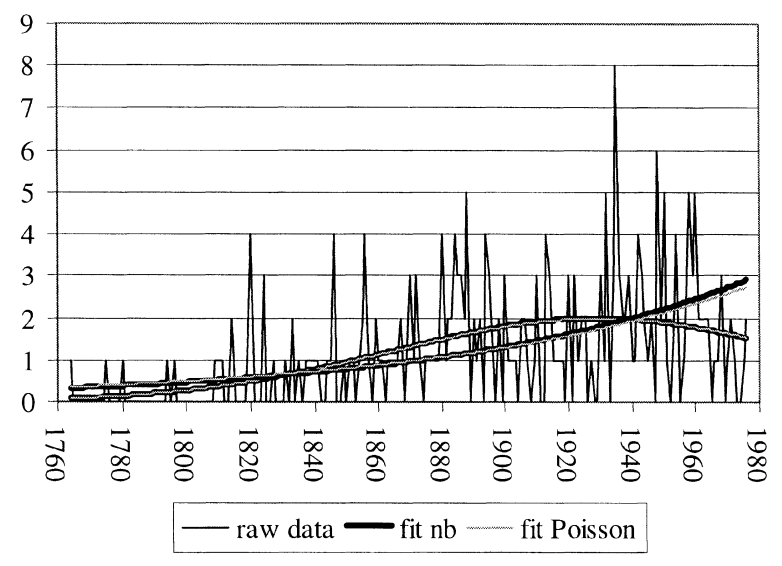

(b) Baker patents

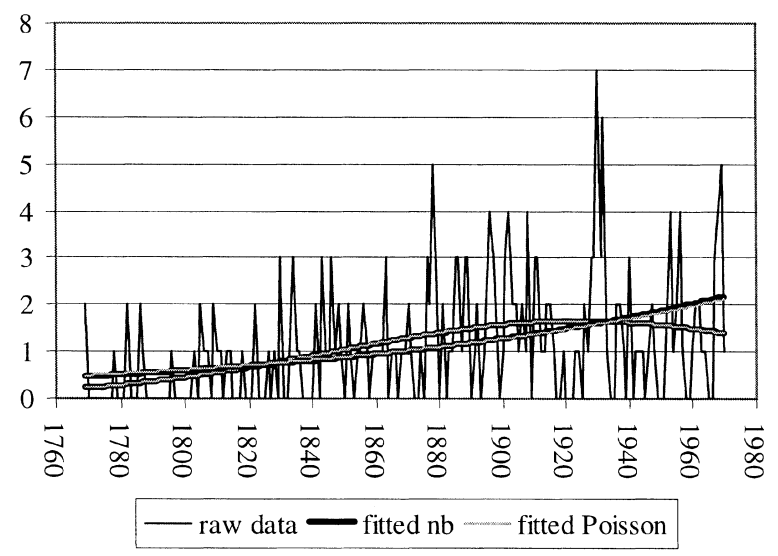

Fig. 2. Raw data and fitted linear and quadratic trends (details of estimation are in Table 1). 
trends, however, autocorrelation vanishes completely in the case of the innovation data. For the patent data, the second-order and third-order polynomial trends leave significant autocorrelation in the residuals at the $10 \%$ or $5 \%$ level. These results suggest that, for the Baker patent time series, the models in Table 1 leave at least some aspects of the long-run dynamics of the time series unexplained, and hence that there is scope for investigating the three other Schumpeterian hypotheses. We now proceed in two ways.

First, we estimate a set of autoregressive models specified in the way explained in Appendix 1. These models take, besides the variables already used, lagged values of the dependent variable itself as explanatory variables. One problem in estimating these models is in determining the exact order of the autoregressive process, i.e., deciding how many lagged terms to include. This is in fact common to all autoregressive models, and the approach most commonly found in the literature is an empirical procedure employing information criteria. These are simple statistics based on the log likelihood value of the models for different autoregressive orders. The simplest is the Aikake Information Criterion (AIC), which we shall use here. The procedure is to find the minimum value of the AIC for a range of autoregressive orders, which in the present case we select as 0-20.

We estimated (and calculated the AIC for) a model with a quadratic exponential time trend plus autoregressive terms. Both a Poisson model and a negative binomial model were estimated for both time series and all autoregressive orders in the range 0-20. For the innovation supersample, the Poisson model has minimum AIC at order 1, while the negative binomial model has minimum AIC at order 12. When the AIC is plotted against the autoregressive order, the Poisson model also has a local minimum that does not differ much in value from the global minimum at order 1 , at order 12 , while the negative binomial model has a local minimum (again not so much different from the global minimum) at order 1 . We therefore document the full set of results for the model at both orders 1 and 12 . When the negative binomial term $\alpha$ is significant, we only document this model, while if it is not significant, we only document the Poisson model.

For the Baker patent time series, the minimum value of the AIC was found at orders 19 (Poisson) and 12 (negative binomial). The Poisson model has a local minimum of the AIC at order 3, which is also documented. In this case, the negative binomial term $\alpha$ is not significant for either the autoregressive order 19 or 3, which is why we document only pure Poisson models. The results for the autoregressive model are documented in Table 2. The autoregressive terms are indicated by the symbol $\rho$.

We note from the table that the significance of the time-parameters $\beta$ is largely unaffected, i.e., that the time trends estimated in Table 1 are robust against the inclusion of autoregressive terms. This does not hold for the negative binomial term $\alpha$. When autoregressive terms are included in the model, this term becomes insignificant in three of the four cases in Table 2 (and, in fact, in most of the undocumented autoregressive models that were run; these results are available on request). The general loss of significance of the negative binomial model points to the fact that the clustering effects that we have attributed above (in our Schumpeter Mark II.0 hypothesis and the discussion of Table 1) to overdispersion may in fact also (and statistically more satisfactorily) be captured by an autoregressive model.

This raises the question as to what pattern of clustering is implied by the estimated autoregressive structure, and whether this pattern is consistent with, for example, our Schumpeter Mark II.1 hypothesis. The answer to this question obviously depends on the value of the estimated $\rho$ parameters. As in a conventional autoregressive model, the values of these parameters have implications for the speed at which 'errors' leave their trace 
Table 2. Regression results, Poisson and negative binomial models, arrival rate function of time and lagged dependent variable

\begin{tabular}{|c|c|c|c|c|}
\hline \multirow[b]{2}{*}{ Coefficient } & \multicolumn{2}{|c|}{ Innovations } & \multicolumn{2}{|c|}{ Baker patents } \\
\hline & (1) & (2) & (3) & (4) \\
\hline$c$ & $-2 \cdot 7656(0 \cdot 000)$ & $-2 \cdot 6037(0 \cdot 000)$ & $-1.6902(0.000)$ & $-3 \cdot 3500(0 \cdot 001)$ \\
\hline$\beta_{1}$ & $0.0424(0.000)$ & $0.0395(0.000)$ & $0.0271(0.000)$ & $0.0526(0.001)$ \\
\hline$\beta_{2}$ & $-0 \cdot 1290^{\mathrm{b}}(0 \cdot 000)$ & $-0 \cdot 1207^{\mathrm{b}}(0 \cdot 000)$ & $-0.8646^{\mathrm{c}}(0 \cdot 001)$ & $-0.1711^{\mathrm{b}}(0.003)$ \\
\hline$\alpha$ & $0 \cdot 1762(0.078)$ & & & \\
\hline$\rho_{1}$ & $-0 \cdot 0184(0 \cdot 871)$ & $0.0431(0.675)$ & $0 \cdot 2651(0 \cdot 010)$ & $0.2342(0 \cdot 056)$ \\
\hline$\rho_{2}$ & & $0 \cdot 6907^{\mathrm{a}}(0 \cdot 947)$ & $0.0933(0 \cdot 302)$ & $0.0748(0.527)$ \\
\hline$\rho_{3}$ & & $-0.0809(0.422)$ & $-0 \cdot 1776(0.056)$ & $-0 \cdot 1914(0 \cdot 122)$ \\
\hline$\rho_{4}$ & & $0 \cdot 1680(0.065)$ & & $0.0622(0.617)$ \\
\hline$\rho_{5}$ & & $0.0516(0.578)$ & & $-0 \cdot 1807(0 \cdot 145)$ \\
\hline$\rho_{6}$ & & $-0 \cdot 1155(0 \cdot 234)$ & & $-0.0612(0.647)$ \\
\hline$\rho_{7}$ & & $-0.0417(0.692)$ & & $-0.0209(0.866)$ \\
\hline$\rho_{8}$ & & $0.0447(0 \cdot 646)$ & & $0.0767(0.497)$ \\
\hline$\rho_{9}$ & & $-0 \cdot 2083(0 \cdot 040)$ & & $-0 \cdot 1685(0 \cdot 143)$ \\
\hline$\rho_{10}$ & & $0.2489(0.010)$ & & $-0 \cdot 1302(0 \cdot 323)$ \\
\hline$\rho_{11}$ & & $-0 \cdot 2508^{\mathrm{a}}(0 \cdot 983)$ & & $-0.1335(0.337)$ \\
\hline$\rho_{12}$ & & $-0.0263(0.801)$ & & $-0 \cdot 1832(0 \cdot 123)$ \\
\hline$\rho_{13}$ & & & & $0 \cdot 1076(0 \cdot 350)$ \\
\hline$\rho_{14}$ & & & & $-0 \cdot 1912(0 \cdot 125)$ \\
\hline$\rho_{15}$ & & & & $-0 \cdot 2145^{\mathrm{a}}(0 \cdot 987)$ \\
\hline$\rho_{16}$ & & & & $0.0867(0.480)$ \\
\hline$\rho_{17}$ & & & & $-0 \cdot 1436(0 \cdot 233)$ \\
\hline$\rho_{18}$ & & & & $-0.0891(0.479)$ \\
\hline & & & & $-0.0843(0.474)$ \\
\hline log likelihood & $-274 \cdot 108$ & $-264 \cdot 790$ & $-263 \cdot 916$ & $-240 \cdot 489$ \\
\hline
\end{tabular}

Notes: $\beta_{1}$ and $\beta_{2}$ are the coefficients on the polynomials of time (1st and 2 nd degree, respectively). $\alpha$ is the parameter for overdispersion in the negative binomial model. $\rho$ indicates the autoregressive terms, the subscript to $\rho$ the order of the autoregressive term. Estimated coefficients are equal to documented coefficients divided by the following factors (absence of a note indicates estimated coefficient is equal to documented coefficient): ${ }^{\mathrm{a}} 100,{ }^{\mathrm{b}} 1,000,{ }^{\mathrm{c}} 10,000,{ }^{\mathrm{d}} 1,000,000,{ }^{\mathrm{e}} 10,000,000$. Numbers between brackets are $p$-values associated with the $t$-statistics.

in the fitted time series. This speed can be visualised by plotting the impulse response function, which, because of the model we have specified in Section 3, must be a multiplicative function rather than the commonly used additive function (see, e.g., Hamilton, 1994, ch. 1).

Figure 3 shows the impulse response function for columns (2)-(4) in Table 2. The function for column (1) is almost completely flat and is therefore not documented. These graphs display the net multiplicative effect of a random innovation in period 0 on the arrival rate in the subsequent periods. For example, the figure for the Baker patent time series at autoregressive order 19 shows that the effect of one 'random extra' innovation in period 0 is to raise the arrival rate in period 19 by slightly more than $10 \%$ compared with a situation without such a random extra innovation (value of $1 \cdot 1$ at the peak is indicated by the arrow). Note that the fact that all three graphs converge to one implies that the effect of a random extra innovation ultimately dies out, i.e., that the process is (trend) stationary. Thus, there will be no persistent long-term effect of a rise in the innovation rate 
Super 12

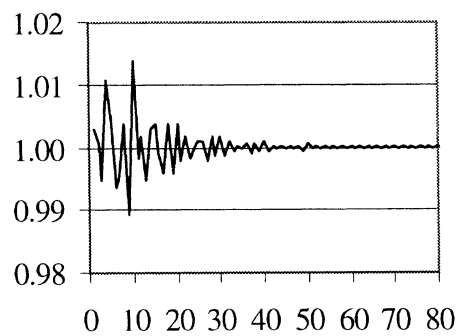

Baker 3

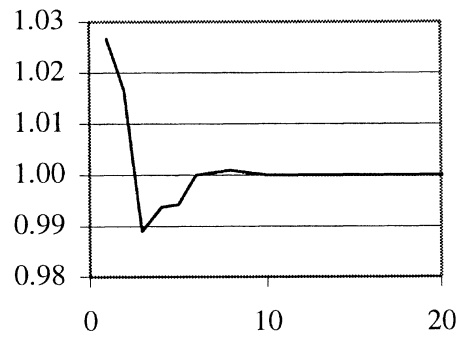

Baker 19

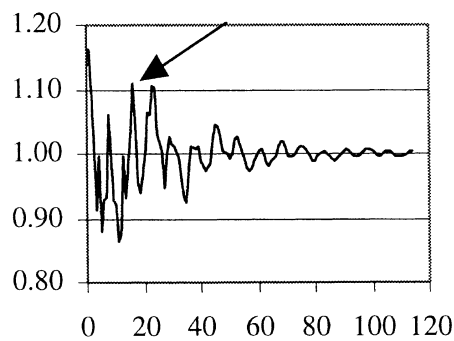

Fig. 3. Impulse-response functions for the autoregressive processes in Table 2.

All three graphs show oscillatory behaviour following a 'random extra' innovation. This is caused by the negative autoregressive parameters ( $\rho s$ ), and leads us to reject the Schumpeter Mark II. 1 hypothesis introduced above. This hypothesis argues that a random extra innovation leaves a slowly dying trace of (relatively) high innovation activity. Such a pattern would result if (most of) the estimated $\rho$ s had high positive values. With the large number of negative values for the autoregressive parameters we obtain in Table 2, the result is the highly irregular and random-looking pattern observed in Figure 3. This is consistent to some extent with the Schumpeter Mark II.0 hypothesis of random clustering, but not with the Schumpeter Mark II. 1 hypothesis.

This still leaves both Schumpeter Mark I hypotheses to be investigated. As a preliminary remark, note that if a strictly periodic pattern (possibly surrounding a trend of some form) existed in the data, one would expect the autoregressive specification to pick this up in some form. In other words, the irregular patterns observed in Figure 3 also have implications for the Schumpeter Mark I hypotheses, in particular, they cast doubt on them. To clarify this further, we employ an additional test to reach a final verdict on Schumpeter Mark I.

This test does not involve data on economic variables, as called for in the Mark I.1 hypothesis. Instead, we investigate the residuals from the regressions in Table 1 to see whether any strictly periodic movements can be detected. To this end, we perform spectral analysis on the standardised residuals (defined above). If the Schumpeter Mark I hypotheses are valid, one would expect clear peaks in the spectral density plot for these residuals, as a result of strictly periodic movements around the estimated trend arrival rate.

Figure 4 displays the spectral density plots for residuals from the Poisson and negative binomial regressions in Table 1. Although there clearly are some peaks in the plots, these are consistent with white-noise data. The overall impression is one of a relatively flat spectrum, which indicates the absence of clear periodic components in the residuals. This holds 


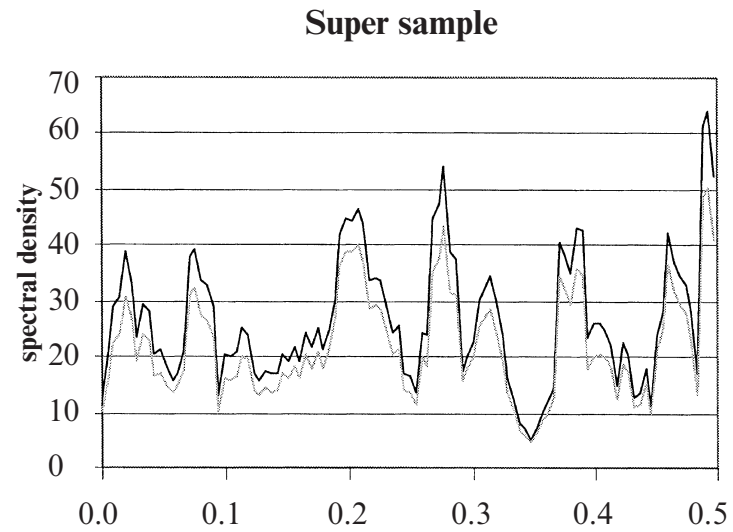

Frequency

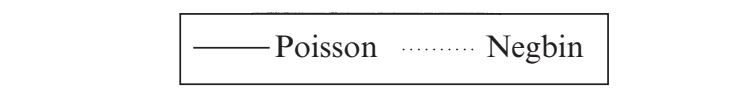

Baker patients

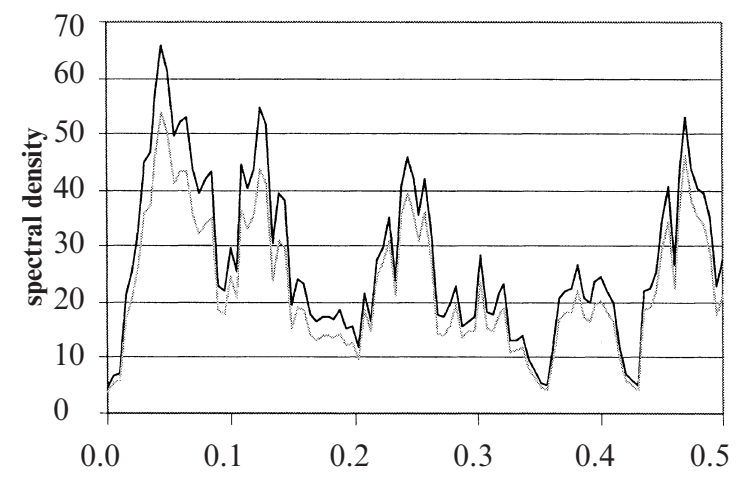

Frequency

Poisson

Negbin

Fig. 4. Spectral density plots for the residuals of the quadratic trend regressions in Table 1.

especially for the supersample innovation time series, and to a somewhat lesser extent for the Baker patent time series.

We thus conclude that the evidence in favour of strictly periodic movements around the (exponential) quadratic trend in the arrival rate is weak. The finding that is closest to our Schumpeter Mark I hypotheses is the 'weak' peak at a cycle length of 20 years in the Baker patent time series.

\section{Summary and conclusions}

This paper pursues a suggestion made by Silverberg and Lehnert (1993) in their discussion of the empirical evidence on the 'Schumpeterian hypothesis' that basic innovations tend to 
cluster. They proposed, in order to overcome the methodological shortcoming of previous work, modelling and estimating a stochastic Poisson process describing the occurrence of basic innovations. We formulate four alternative hypotheses bearing on the Schumpeterian clustering hypothesis that are amenable to statistical testing. We then estimated a model of the trend in the arrival rate of basic innovations, and found that a quadratic exponential trend fits the data best (compared with a linear or third-degree trend). Investigating the residuals of this regression for periodic cycles around the trend, we found essentially no evidence in favour of such strong periodic clustering.

A weaker version of the clustering theory interprets clusters as themselves randomly distributed. Evidence for this interpretation is presented in the form of estimates of the negative binomial parameter, which is found to be significantly different from zero.

A different version of random clustering occurs when random events tend to 'persist' in time, for example owing to an autoregressive process. We have estimated autoregressive Poisson and negative binomial models (again based on a quadratic exponential trend), and found that these models may indeed improve the fit. However, by plotting the impulse response functions, we showed that innovation impulses do not lead to long periods of above-normal innovative activity. Rather, such impulses die out in an oscillatory way, and leave a rather irregular and random-looking trace. We interpret this as evidence against a knock-on effect being the source of clustering.

We are thus left with the conclusion that the only form of clustering of basic innovations that is consistent with the data is 'random clustering' superimposed on a second-degree trend. Basic innovations, while they arrive in clusters, do not engender higher rates of basic innovative activity (although they may initiate periods of higher incremental innovation not picked up in our data), nor are these clusters in any way periodic. Thus even if we have just come through a period of exceptionally high innovation in the 1990s (the purported 'new economy'), this is no guarantee that innovation rates will remain at historically high levels in the future. To what extent these rates are influenced by the macroeconomic context is a subject we hope to study further.

\section{Bibliography}

Baker, R. 1976. New and Improved: Inventors and Inventions that Have Changed the Modern World, London, British Museum Publications

Cameron, A. C. and Trivedi, P. K. 1998. Regression Analysis of Count Data. Econometric Society Monographs, vol. 30, Cambridge, Cambridge University Press

Cincera, M. 1997. Patents, R\&D and technological spillovers at the firm level: some evidence from econometric count models for panel data, fournal of Applied Econometrics, vol. 12, 265-80

Crepon, B. and Duguet, E. 1997A. Estimating the innovation function from patent numbers: GMM on count panel data, fournal of Applied Econometrics, vol. 12: 243-63

Crepon, B. and Duguet, E. 1997B. Research and development, competition and innovation pseudomaximum likelihood and simulated maximum likelihood methods applied to count data models with heterogeneity, fournal of Econometrics, vol. 79, 355-78

Freeman, C. and Perez, C. 1988. Structural crises of adjustment, business cycles and investment behaviour, in Dosi, G., Freeman, C., Nelson, R., Silverberg, G. and Soete, L. (eds), Technical Change and Economic Theory, London, Pinter

Freeman, C. and Soete, L. 1997. The Economics of Industrial Innovation, 3rd edn, London and Washington, Pinter

Freeman, C., Clark, J. and Soete, L. 1982. Unemployment and Technical Innovation, London, Pinter

Gordon, R. J. 2000. Does the 'New Economy' measure up to the great inventions of the past?, fournal of Economic Perspectives, vol. 14, 49-74

Greene, W. 1995. Econometric Analysis, 3rd edn, New Jersey, Prentice Hall 
Hamilton, J. D. 1994. Time Series Analysis, Princeton, NJ, Princeton University Press

Haustein, H.-D. and Neuwirth, E. 1982. Long waves in world industrial production, energy consumption, innovations, inventions, and patents and their identification by spectral analysis, Technological Forecasting and Social Change, vol. 22, 53-89

Hausman, J., Hall, B. H. and Griliches, Z. 1984. Econometric models for count data with an application to the patents-R\&D relationship, Econometrica, vol. 52, 909-38

Jewkes, J., Sawers, D. and Stillerman, R. 1958. The Sources of Invention, London, Macmillan

Kleinknecht, A. 1981. Observations on the Schumpeterian swarming of innovations, Futures, vol. 13, 293-307

Kleinknecht, A. 1987. Innovation Patterns in Crisis and Prosperity. Schumpeter's Long Cycle Reconsidered, London, Macmillan

Kleinknecht, A. 1990. Are there Schumpeterian waves of innovations?, Cambridge fournal of Economics, vol. 14, 81-92

Kondratieff, N. D. 1926/1935, Die langen Wellen der Konjunktur, Archiv für Sozialwissenschaft und Sozialpolitik, vol. 56, 573-609 (English translation: The long waves in economic life, The Review of Economic Statistics, vol. 17, 105-15)

Kuznets, S. 1940. Schumpeter's business cycles, American Economic Review, vol. 30, 257-71

Mensch, G. 1975/1979. Das technologische Patt, Frankfurt, Umschau (English translation: Stalemate in Technology. Innovations Overcome Depression, Cambridge, Ballinger)

Sahal, D. 1974. Generalized Poisson and related models of technological innovation, Technological Forecasting and Social Change, vol. 6, 403-36

Schumpeter, J. A. 1939. Business Cycles: A Theoretical, Historical and Statistical Analysis of the Capitalist Process, New York, McGraw-Hill (page numbers quoted in the text refer to the abridged version reprinted in 1989 by Porcupine Press, Philadelphia)

Silverberg, G. and Lehnert, D. 1993. Long waves and 'evolutionary chaos' in a simple Schumpeterian model of embodied technical change, Structural Change and Economic Dynamics, vol. 4, 9-37

Solomou, S. 1986. Innovation clusters and Kondratieff long waves in economic growth, Cambridge fournal of Economics, vol. 10, 101-12

Ten Raa, T. and Wolff, E. N. 2000. Engines of growth in the U.S. economy, Structural Change and Economic Dynamics, vol. 11, 433-72

van Duijn, J. J. 1983. The Long Wave in Economic Life, London, Allen \& Unwin

\section{Appendix 1: Poisson regression}

The starting point for all statistical analysis in this paper is the (time-homogeneous) Poisson process, which makes the simplifying assumption that the probability of occurrence of an innovation within a given interval of time is independent of previous innovations and independent of time. The probability of $y$ innovations during an interval of time $T$ is given by

$$
\operatorname{Prob}(y)=\frac{\mathrm{e}^{-\lambda T}(\lambda T)^{y}}{y !}
$$

where $y \in \mathbb{N}$, and $\lambda$ is a parameter, often referred to as the arrival rate of the Poisson process. Note that $\lambda$ is not necessarily an integer number. It is easily shown that the expected number of events per unit time is $\lambda$, which also happens to be the variance of the distribution. Note that time series generated from a time-homogeneous Poisson process will not display a completely uniform pattern of occurrences of the random event. In other words, to the naïve eye, some clustering will characterise even this simplest point process.

The parameter $\lambda$ may also be specified endogenously, for example as $\ln \lambda=\boldsymbol{\beta}^{\prime} \mathbf{x}$, where $\mathbf{x}$ is a vector of independent variables, and $\boldsymbol{\beta}$ is a parameter vector. Other specifications for $\lambda$ are possible, but the example above is often used because it is convenient for estimation purposes (using $\ln \lambda$ as the independent variable ensures non-negative arrival rates). In this case, the parameter vector $\boldsymbol{\beta}$ can be interpreted as a vector of elasticities of the arrival rate with respect to the independent variables. Such an approach allows us to test the assumption that the Poisson process is time-homogeneous by setting up the null hypothesis that all elements of $\boldsymbol{\beta}$, including one corresponding to time itself, are equal to zero. 
One problem with the Poisson model is its peculiarity that the mean and variance of the distribution are equal. Empirical data often show a larger variance than mean for the dependent variable, a phenomenon termed 'overdispersion'. Hausman et al. (1984), for example, observed overdispersion in their firm-level patent database. A model that can account for overdispersion may be obtained by adding an unobserved random effect to the mean of the Poisson distribution (Hausman et al., 1984). This leads to a modified probability distribution of the type:

$$
\operatorname{Prob}(Y=y \mid u)=\frac{\mathrm{e}^{-\lambda u}(\lambda u)^{y}}{y !}
$$

where $u$ is a random variable for which some distribution must be assumed (see Greene, 1995, p. 939). The variable $u$ may, for example, reflect random noise, or cross-sectional heterogeneity (when the model is estimated in the cross-sectional dimension). Assuming that $u$ is gamma distributed, one obtains the following unconditional distribution (Cameron and Trivedi, 1998, p. 71):

$$
\operatorname{Prob}(Y=y \mid \mathbf{x})=\frac{\Gamma\left(\alpha^{-1}+y\right)}{\Gamma(y+1) \Gamma\left(\alpha^{-1}\right)} r^{y}(1-r) \alpha^{-1}, \text { where } \mathrm{r}=\frac{\lambda}{\lambda+\alpha^{-1}} .
$$

This distribution is known as the negative binomial distribution and has mean $\lambda$ and variance $\lambda(1+\lambda)$ for $\alpha>0$. When $\lambda$ approaches 0 , the model reduces to a standard Poisson model, and the variance becomes equal to $\lambda$ again. The negative binomial model can also be estimated using a maximum likelihood method. A test of the Poisson against the negative binomial distribution can be implemented by means of a Likelihood Ratio test, Wald test or $t$-test (Green, 1995) of the null hypothesis $\alpha=0$.

In the context of time series and the hypothesis of clustering of events (innovations) in specific time periods, the correlation structure of the residuals becomes of interest. Cameron and Trivedi (1998) suggest investigating the standardised residual $z_{t}=\left(y_{t}-m_{t}\right) / \sqrt{\sigma}_{t}$, where $y_{t}$ is the observed (integer) value, $m_{t}$ is the sample mean value and $\sigma_{t}$ is the sample variance. When a Poisson model is fitted, $m_{t}=$ $\sigma_{t}$ is equal to the estimated arrival rate. Cameron and Trivedi (1998) then suggest applying the BoxPierce portmanteau, the Box-Ljung statistic (which has better small sample properties) or a slightly modified statistic that guards against incorrect standardisation, to test for the null-hypothesis that all autocorrelations of the residuals up to lag $k$ are zero.

In case such a null-hypothesis is rejected, various ways are suggested (Cameron and Trivedi, 1998, Section 7.5) of specifying a model to deal with the autocorrelated residuals. The method closest to our original Poisson regression approach is to estimate an autoregressive model, i.e., to include lagged values of the dependent variable in the regression as independent variables. The simplest model is called exponential feedback, and assumes $\ln \lambda_{t}=\boldsymbol{\beta}^{\prime} \mathbf{x}_{t}+\rho y_{t-1}$. This, however, implies explosive behaviour for $\rho>0$. In order to rule out this undesirable property, Cameron and Trivedi suggest using $\lambda_{t}=\exp \left(\boldsymbol{\beta}^{\prime} \mathbf{x}_{t}\right) \Sigma_{k}\left(y^{\star}{ }_{t-k}\right)_{k}^{\rho}$, where $y^{\star}$ is a transformation of $y$ to ensure positive values, $y^{\star}=\max (1 / 2, y)$, or $y^{\star}=y+1 / 2$. 
Appendix 2: Data on basic innovations

Table A1. The supersample of basic innovations

\begin{tabular}{|c|c|c|c|c|c|}
\hline $\begin{array}{l}\text { Item } \\
\text { number }\end{array}$ & Innovation & Year & $\begin{array}{l}\text { Item } \\
\text { number }\end{array}$ & Innovation & Year \\
\hline 89 & Spinning machine & 1764 & 192 & Siemens-Martin steel & 1864 \\
\hline 90 & Steam engine & 1775 & 112 & Paper from wood & 1865 \\
\hline 91 & Automatic band loom & 1780 & 4 & Deep-sea cable & 1866 \\
\hline 92 & Sliding carriage & 1794 & 50 & Dynamite & 1867 \\
\hline 81 & Blast furnace & 1796 & 75 & Dynamo & 1867 \\
\hline 48 & Steam ship & 1809 & 113 & Commutator & 1869 \\
\hline 95 & Whitney's method & 1810 & 60 & Typewriter & 1870 \\
\hline 80 & Crucible steel & 1811 & 193 & Celluloid & 1870 \\
\hline 183 & Street lighting (gas) & 1814 & 194 & Combine harvester & 1870 \\
\hline 184 & Mechanical printing press & 1814 & 85 & Margarine & 1871 \\
\hline 78 & Lead chamber process & 1819 & 6 & Thomas steel & 1872 \\
\hline 77 & Quinine & 1820 & 46 & Reinforced concrete & 1872 \\
\hline 98 & Isolated conduction & 1820 & 114 & Drum rotor & 1872 \\
\hline 99 & Rolled wire & 1820 & 115 & Preservatives & 1873 \\
\hline 100 & Cartwright's loom & 1820 & 51 & Sulphuric acid & 1875 \\
\hline 3 & Steam locomotive & 1824 & 195 & Four-stroke engine & 1876 \\
\hline 61 & Cement & 1824 & 5 & Telephone & 1877 \\
\hline 66 & Puddling furnace & 1824 & 116 & Nickel & 1878 \\
\hline 101 & Pharma fabrication & 1827 & 53 & Electric railway & 1879 \\
\hline 102 & Calcium chlorate & 1831 & 12 & Incandescent lamp & 1880 \\
\hline 79 & Telegraphy & 1833 & 47 & Water turbine & 1880 \\
\hline 103 & Urban gas & 1833 & 117 & Jodoforme & 1880 \\
\hline 104 & Rolled rails & 1835 & 196 & Half-tone process & 1880 \\
\hline 87 & Electric motor & 1837 & 197 & Electric power station & 1881 \\
\hline 67 & Photography & 1838 & 118 & Veronal & 1882 \\
\hline 9 & Bicycle & 1839 & 119 & Cable & 1882 \\
\hline 88 & Vulcanised rubber & 1840 & 120 & Antipyrin & 1883 \\
\hline 7 & Arc lamp & 1841 & 121 & Coals whisks & 1883 \\
\hline 105 & Jacquard loom & 1844 & 10 & Steam turbine & 1884 \\
\hline 106 & Lathe & 1845 & 122 & Chloroform & 1884 \\
\hline 107 & Inductor & 1846 & 198 & Punched card & 1884 \\
\hline 108 & Electrodynamic measuring & 1846 & 199 & Cash register & 1884 \\
\hline 185 & Rotary press & 1846 & 38 & Syntethic fertilisers & 1885 \\
\hline 186 & Anaesthetics & 1846 & 52 & Transformer & 1885 \\
\hline 187 & Steel (puddling process) & 1849 & 123 & Synthetic alkaloids & 1885 \\
\hline 188 & Sewing machine & 1851 & 124 & Magnesium & 1886 \\
\hline 109 & Plaster of paris & 1852 & 125 & Electric welding & 1886 \\
\hline 14 & Aluminium & 1854 & 200 & Linotype & 1886 \\
\hline 40 & Safety match & 1855 & 72 & Phonographe & 1887 \\
\hline 189 & Bunsen burner & 1855 & 126 & Electrolyse & 1887 \\
\hline 36 & Refined steel/Bessemer steel & 1856 & 28 & Motor car & 1888 \\
\hline 84 & Steel pen/Fountain pen & 1856 & 59 & Pneumatic tyre & 1888 \\
\hline 110 & Tare colours industry & 1856 & 127 & Electric counter & 1888 \\
\hline 111 & Baking powder & 1856 & 201 & Portable camera & 1888 \\
\hline 190 & Elevator & 1857 & 202 & Alternating-current generator & 1888 \\
\hline 76 & Lead battery & 1859 & 86 & Man-made fibres & 1890 \\
\hline 191 & Drilling for oil & 1859 & 128 & Chemical fibres & 1890 \\
\hline 54 & Internal combustion engine & 1860 & 129 & Melting by induction & 1891 \\
\hline 39 & Soda works & 1861 & 83 & Acetylene welding & 1892 \\
\hline 19 & Anilin dyes & 1863 & 130 & Accounting machine & 1892 \\
\hline
\end{tabular}


Table A1. (continued)

\begin{tabular}{|c|c|c|c|c|c|}
\hline $\begin{array}{l}\text { Item } \\
\text { number }\end{array}$ & Innovation & Year & $\begin{array}{l}\text { Item } \\
\text { number }\end{array}$ & Innovation & Year \\
\hline 41 & Cinematography & 1894 & 223 & Freon refrigerants & 1931 \\
\hline 131 & Antitoxines & 1894 & 34 & Crease-resistant fabrics & 1932 \\
\hline 203 & Motor cycle & 1894 & 224 & Gas turbine & 1932 \\
\hline 204 & Monotype & 1894 & 225 & Polyvinylchloride & 1932 \\
\hline 8 & Diesel engine & 1895 & 226 & Antimalaria drugs & 1932 \\
\hline 132 & Drilling machine for mining & 1895 & 227 & Sulfa drugs & 1932 \\
\hline 205 & Electric automobile & 1895 & 56 & Fluor lamp & 1934 \\
\hline 206 & $\mathrm{X}$-rays & 1896 & 146 & Diesel locomotive & 1934 \\
\hline 37 & Aspirin & 1898 & 147 & Fischer-Tropsch procedure & 1934 \\
\hline 133 & Arc welding & 1898 & 11 & Radar & 1935 \\
\hline 134 & Air ship & 1900 & 13 & Ballpoint pen & 1935 \\
\hline 135 & Synthesis of indigo & 1900 & 30 & Rockets/guided missiles & 1935 \\
\hline 207 & Submarine & 1900 & 31 & Plexiglas & 1935 \\
\hline 136 & Holing machine & 1901 & 62 & Magnetophone & 1935 \\
\hline 137 & Electric steel making & 1902 & 70 & Catalytic cracking & 1935 \\
\hline 208 & Safety razor & 1903 & 82 & Colour photo & 1935 \\
\hline 209 & Viscose rayon & 1905 & 148 & Gasoline & 1935 \\
\hline 210 & Vacuum cleaner & 1905 & 16 & Television & 1936 \\
\hline 138 & Acetylene & 1906 & 149 & Photoelectric cell & 1936 \\
\hline \multirow[t]{2}{*}{211} & \multicolumn{2}{|c|}{ Chemical accelerator for rubber } & 228 & FM radio & 1936 \\
\hline & vulcanisation & 1906 & 150 & Vitamins & 1937 \\
\hline 212 & Electric washing machine & 1907 & 229 & Electron microscope & 1937 \\
\hline 15 & Gyro compass & 1909 & 20 & Helicopter & 1938 \\
\hline 2 & Aeroplane & 1910 & 230 & Nylon & 1938 \\
\hline 69 & Bakelite (Phenol plastics) & 1910 & 21 & Polethylene & 1939 \\
\hline 139 & High-voltage isolation & 1910 & 55 & Automatic gears & 1939 \\
\hline 65 & Vacuum tube & 1913 & 151 & Hydraulic gear & 1939 \\
\hline 71 & Assembly line & 1913 & 27 & Antibiotics (penicillin) & 1940 \\
\hline 213 & Thermal cracking & 1913 & 152 & Cotton picker & 1941 \\
\hline 214 & Domestic refrigerator & 1913 & 43 & Jet engine/plane & 1942 \\
\hline 140 & Ammonia synthesis & 1914 & 45 & DDT & 1942 \\
\hline 141 & Tractor & 1914 & 153 & Heavy water & 1942 \\
\hline 215 & Stainless steel & 1914 & 231 & Continuous catalytic cracking & 1942 \\
\hline 142 & Tank & 1915 & 24 & Silicones & 1943 \\
\hline 32 & Synthetic rubber & 1916 & 232 & Aerosol spray & 1943 \\
\hline 42 & Cellophane & 1917 & 233 & High-energy accelerators & 1943 \\
\hline 1 & Zip fastener & 1918 & 44 & Streptomycin & 1944 \\
\hline 29 & AM radio & 1920 & 154 & Titan reduction & 1944 \\
\hline 216 & Acetate rayon & 1920 & 22 & Sulzer loom & 1945 \\
\hline 217 & Continuous thermal cracking & 1920 & 68 & Oxygen steelmaking & 1946 \\
\hline 26 & Synthetic detergents & 1922 & 234 & Phototype & 1946 \\
\hline 57 & Insulin & 1922 & 49 & Numerically controlled & \\
\hline 143 & Synthesis of methanol & 1922 & & machine tools & 1948 \\
\hline 35 & Continuous rolling & 1923 & 58 & Continuous steel making & 1948 \\
\hline 218 & Dynamic loudspeaker & 1924 & 235 & Orlon & 1948 \\
\hline 219 & Leica camera & 1924 & 236 & Cortisone & 1948 \\
\hline 144 & Deep-frozen food & 1925 & 237 & Long-playing record & 1948 \\
\hline 220 & Electric record player & 1925 & 238 & Polaroid land camera & 1948 \\
\hline 145 & Coal hydrogenation & 1927 & 155 & Thonet furniture & 1949 \\
\hline 17 & Power steering & 1930 & 156 & Polyester & 1949 \\
\hline 221 & Polystyrene & 1930 & 18 & Computer & 1950 \\
\hline 222 & Rapid freezing & 1930 & 23 & Transistor & 1950 \\
\hline
\end{tabular}


Table A1. (continued)

\begin{tabular}{llllll}
\hline $\begin{array}{l}\text { Item } \\
\text { number }\end{array}$ & \multicolumn{1}{c}{ Innovation } & Year & $\begin{array}{l}\text { Item } \\
\text { number }\end{array}$ & \multicolumn{1}{c}{ Innovation } & Year \\
& & & & & \\
25 & Xerography & 1950 & 248 & Polycarbonates & 1960 \\
239 & Terylene & 1950 & 249 & Contraceptive pill & 1960 \\
240 & Radial tyre & 1950 & 250 & Hovercraft & 1960 \\
157 & Double-floor railway & 1951 & 64 & Integrated circuit & 1961 \\
158 & Cinerama & 1953 & 169 & Planar process & 1961 \\
241 & Colour television & 1953 & 73 & Laser & 1962 \\
33 & Nuclear energy & 1954 & 251 & Communication satellite & 1962 \\
242 & Gas chromatograph & 1954 & 170 & Implementation of ions & 1963 \\
243 & Remote control & 1954 & 171 & Epitaxy & 1963 \\
244 & Silicon transistor & 1954 & 172 & Synthetic leather & 1964 \\
159 & Air-compressed building & 1956 & 173 & Transistor laser & 1964 \\
160 & Atomic ice breaker & 1957 & 174 & Optoelectronic diodes & 1966 \\
161 & Space travel & 1957 & 252 & Wankel-motor & 1967 \\
162 & Stitching bond & 1958 & 74 & Video & 1968 \\
163 & Holography & 1958 & 175 & Light-emitting fluor display & 1968 \\
164 & Transistor radio & 1958 & 176 & Minicomputers & 1968 \\
165 & Diffusion process & 1958 & 177 & Quartz watches & 1970 \\
245 & Fuel cell & 1958 & 63 & Microprocessor & 1971 \\
166 & Quartz clocks & 1959 & 178 & Electronic calculator & 1971 \\
246 & Polyacetates & 1959 & 179 & Light-tunnel technology & 1972 \\
247 & Float glass & 1959 & 180 & 16-bit microprocessor & 1975 \\
167 & Maser & 1960 & 181 & 16384 bit RAM & 1976 \\
168 & Micro modules & 1960 & 182 & Microcomputer & 1976 \\
& & & & & \\
\hline
\end{tabular}

Note: Items $1-88$ occur in both databases, items $89-182$ occur only in Haustein and Neuwirth data, items $183-252$ occur only in van Duijn data. 
Table A2. Innovations in the Haustein and Neuwirth time series that were matched to innovations in the van Duijn time series

\begin{tabular}{|c|c|c|c|c|c|}
\hline Innovation & Year & $\begin{array}{l}\text { To which } \\
\text { item in } \\
\text { merged } \\
\text { series? }\end{array}$ & Innovation & Year & $\begin{array}{l}\text { To which } \\
\text { item in } \\
\text { merged } \\
\text { series? }\end{array}$ \\
\hline Blast furnace & 1796 & to 81 & Aspirin & 1898 & to 37 \\
\hline Steamer & 1809 & to 48 & Steel concrete & 1902 & to 46 \\
\hline Crucible cast steel & 1811 & to 80 & Gyro compass & 1909 & to 15 \\
\hline Lead-chamber process & 1819 & to 78 & Pheno plastics & 1910 & to 69 \\
\hline Chinin fabrication & 1820 & to 77 & Airplane & 1911 & to 2 \\
\hline Locomotive & 1824 & to 3 & Conveyor belt production & 1913 & to 71 \\
\hline Puddling furnace & 1824 & to 66 & Synthetic rubber & 1916 & to 32 \\
\hline Telegraphy & 1833 & to 79 & Electronic tubes & 1920 & to 65 \\
\hline Photography & 1838 & to 67 & Detergents/synthetic & 1922 & to 26 \\
\hline Bicycle (pedal) & 1839 & to 9 & Radio & 1922 & to 29 \\
\hline Cement & 1844 & to 61 & Insulin & 1922 & to 57 \\
\hline Arc lamp & 1844 & to 7 & Zip fastener & 1923 & to 1 \\
\hline Generator of current & 1849 & to 87 & Continuous rolling & 1923 & to 35 \\
\hline Hard rubber & 1852 & to 88 & Cellophane & 1926 & to 42 \\
\hline Aluminium & 1854 & to 14 & Power steering & 1930 & to 17 \\
\hline Refined steel & 1856 & to 36 & Crease-resistant fabrics & 1932 & to 34 \\
\hline Steel pen & 1856 & to 84 & Fluorescent lamp & 1934 & to 56 \\
\hline Lead accumulator & 1859 & to 76 & Ball-point pen & 1935 & to 13 \\
\hline Soda works & 1861 & to 39 & Rockets & 1935 & to 30 \\
\hline Production of analin & 1863 & to 19 & Plexiglass & 1935 & to 31 \\
\hline Deep sea cable & 1866 & to 4 & Magnetophone & 1935 & to 62 \\
\hline Safety matches & 1866 & to 40 & Catalytic cracking & 1935 & to 70 \\
\hline Dynamite & 1867 & to 50 & Colour film & 1935 & to 82 \\
\hline Dynamo & 1867 & to 75 & $\mathrm{TV}$ & 1936 & to 16 \\
\hline Thomas steel & 1872 & to 6 & Radar & 1939 & to 11 \\
\hline Typewriter & 1873 & to 60 & Helicopter & 1939 & to 20 \\
\hline Sulphuric acid production & 1875 & to 51 & Automatic gears & 1939 & to 55 \\
\hline Telephone & 1878 & to 5 & Synthetic fibres & 1939 & to 86 \\
\hline Electric locomotive & 1879 & to 53 & Antibiotics & 1940 & to 27 \\
\hline Incandescent lamp & 1880 & to 12 & DDT & 1942 & to 45 \\
\hline Cooking fat & 1882 & to 85 & Jet engine & 1943 & to 43 \\
\hline Electricity & 1882 & to 87 & Streptomycine & 1944 & to 44 \\
\hline Electric heating & 1882 & to 87 & Sulzer loom & 1945 & to 22 \\
\hline Long-distance conduction & 1882 & to 87 & Silicons & 1946 & to 24 \\
\hline Synthetic fertilisers & 1885 & to 38 & Oxygen-process & 1946 & to 68 \\
\hline Transformers & 1885 & to 52 & NC machines & 1948 & to 49 \\
\hline Combustion engine & 1886 & to 54 & Continuous steelmaking & 1948 & to 58 \\
\hline Phonograph & 1887 & to 72 & Computer & 1950 & to 18 \\
\hline Tyres with air compression & 1888 & to 59 & Transistor & 1950 & to 23 \\
\hline Water turbine & 1890 & to 47 & Xerographie & 1950 & to 50 \\
\hline Welding by acetylene & 1892 & to 83 & Polyethylene & 1953 & to 21 \\
\hline Steam turbine & 1895 & to 10 & Nuclear power station & 1954 & to 33 \\
\hline Automobile & 1895 & to 28 & Integrated circuits & 1961 & to 64 \\
\hline Cinematography & 1895 & to 41 & Laser & 1962 & to 73 \\
\hline Electric railway & 1895 & to 53 & Video-tape recorder & 1968 & to 74 \\
\hline Diesel engine & 1897 & to 8 & Microprocessor & 1971 & to 63 \\
\hline
\end{tabular}


Table A3. Innovations in the van Duijn time series that were matched to innovations in the Haustein and Neuwirth time series

\begin{tabular}{|c|c|c|}
\hline Innovation & Year & $\begin{array}{l}\text { To which item in } \\
\text { merged series? }\end{array}$ \\
\hline Crucible steel & 1811 & to 80 \\
\hline Sulphuric acid (lead chamber process) & 1819 & to 78 \\
\hline Quinine & 1820 & to 77 \\
\hline Portland cement & 1824 & to 61 \\
\hline Coke blast furnace & 1829 & to 81 \\
\hline Steam locomotive & 1830 & to 3 \\
\hline Puddling furnace & 1832 & to 66 \\
\hline Electric motor & 1837 & to 87 \\
\hline Steamship (Atlantic crossing) & 1838 & to 48 \\
\hline Photography & 1839 & to 67 \\
\hline Electric telegraph & 1839 & to 79 \\
\hline Vulcanised rubber & 1840 & to 88 \\
\hline Arc lamp & 1841 & to 7 \\
\hline Safety match & 1855 & to 40 \\
\hline Bessemer steel & 1856 & to 36 \\
\hline Lead battery & 1859 & to 76 \\
\hline Internal combustion engine & 1860 & to 54 \\
\hline Sodium carbonate & 1861 & to 39 \\
\hline Aniline dyes & 1865 & to 19 \\
\hline Atlantic telegraph cable & 1866 & to 4 \\
\hline Dynamite & 1867 & to 50 \\
\hline Dynamo & 1867 & to 75 \\
\hline Typewriter & 1870 & to 60 \\
\hline Margarine & 1871 & to 85 \\
\hline Reinforced concrete & 1872 & to 46 \\
\hline Sulphuric acid & 1875 & to 51 \\
\hline Telephone & 1877 & to 5 \\
\hline Electric railway & 1879 & to 53 \\
\hline Thomas oven & 1879 & to 6 \\
\hline Incandescent lamp & 1880 & to 12 \\
\hline Water turbine & 1880 & to 47 \\
\hline Steam turbine & 1884 & to 10 \\
\hline Fountain pen & 1884 & to 84 \\
\hline Transformer & 1885 & to 52 \\
\hline Bicycle & 1885 & to 9 \\
\hline Aluminium & 1887 & to 14 \\
\hline Motor car & 1888 & to 28 \\
\hline Cylindrical record player & 1888 & to 72 \\
\hline Pneumatic tyre & 1889 & to 59 \\
\hline Mechanical record player & 1889 & to 72 \\
\hline Rayon (nitro-cellulose pr.) & 1892 & to 86 \\
\hline Motion picture film & 1894 & to 41 \\
\hline Diesel engine & 1895 & to 8 \\
\hline Rayon (cuprammonium pr.) & 1898 & to 86 \\
\hline Aspririn & 1899 & to 37 \\
\hline Oxy-acetylene welding & 1903 & to 83 \\
\hline Airplane & 1910 & to 2 \\
\hline Bakelite & 1910 & to 69 \\
\hline Gyro compass & 1911 & to 15 \\
\hline Synthetic fertiliser (nitrogen) & 1913 & to 38 \\
\hline
\end{tabular}


Table A3. (continued)

\begin{tabular}{lll}
\hline Innovation & Year & $\begin{array}{l}\text { To which item in } \\
\text { merged series? }\end{array}$ \\
\hline Vacuum tube & & \\
Assembly line & 1913 & to 65 \\
Cellophane & 1913 & to 71 \\
Zip fastener & 1917 & to 42 \\
AM radio & 1918 & to 1 \\
Continuous hot strip rolling & 1920 & to 29 \\
Insulin & 1923 & to 35 \\
Synthetic detergents & 1923 & to 57 \\
Synthetic rubber & 1930 & to 26 \\
Crease-resisting fabrics & 1932 & to 32 \\
Radar & 1932 & to 34 \\
Plexiglas & 1935 & to 11 \\
Magnetic tape recorder & 1935 & to 31 \\
Colour photography & 1935 & to 62 \\
Television & 1935 & to 82 \\
Catalytic cracking & 1936 & to 16 \\
Helicopter & 1937 & to 70 \\
Fluorescent lamp & 1938 & to 20 \\
Polyethylene & 1938 & to 56 \\
Penicillin & 1939 & to 21 \\
Guided missiles & 1942 & to 27 \\
Jet airplane & 1942 & to 30 \\
DDT & 1942 & to 43 \\
Silicones & 1942 & to 45 \\
Ball-point pen & 1943 & to 24 \\
Streptomycin & 1945 & to 13 \\
Automatic transmission (passenger cars) & 1946 & to 44 \\
Sulzer loom & 1948 & to 55 \\
Xerography & 1950 & to 22 \\
Power steering (passenger cars) & 1950 & to 25 \\
Electronic computer & 1951 & to 17 \\
Transistor & 1951 & to 18 \\
Continuous casting of steel & 1951 & to 23 \\
Oxygen steel making & 1952 & to 58 \\
Numerically controlled machine tools & 1953 & to 68 \\
Nuclear energy & 1955 & to 49 \\
Integrated circuit & 1956 & to 33 \\
Laser & 1961 & to 64 \\
Video cassette recorder & 1967 & to 73 \\
Micro-processor & 1970 & to 74 \\
& 1971 & to 63 \\
\hline
\end{tabular}


